\title{
Clinical Assessment of the Use of Propinox Hydrochloride and Scopolamine Hydrochloride in the Treatment of Abdominal Colic: A Retrospective, Comparative Study
}

\author{
Helio Rzetelna 1,2,3,4,5, Carlos Frederico Porto Alegre Rosa 5,6,7,8, Mario Kirzner,4,9, \\ Lucas Pereira Jorge de Medeiros ${ }^{1,2,10}$, Camila Melo ${ }^{11}$, Marcia Gonçalves Ribeiro' ${ }^{12}$, \\ Lisa Oliveira'13, José Galvão Alves ${ }^{5,9}$, Mauro Geller12,13,14* \\ ${ }^{1}$ Gastroenterology Department, Universidade Federal do Rio de Janeiro (UFRJ), Rio de Janeiro, Brazil \\ ${ }^{2}$ Clinical Medicine Department, Centro Universitário Volta Redonda (UNIFOA), Volta Redonda, Brazil \\ ${ }^{3}$ Clinical Medicine and Gastroenterology Department, Universidade Estácio de Sá (UNESA) Rio de Janeiro, Brazil \\ ${ }^{4}$ Clinical Medicine Department, Escola de Medicina Souza Marques, Rio de Janeiro, Brazil \\ ${ }^{5}$ Inflammatory Bowel Diseases Outpatient Unit-18 a enfermaria da Santa Casa da Misericórdia do Rio de \\ Janeiro, Rio de Janeiro, Brazil \\ ${ }^{6}$ Federação Brasileira de Gastroenterologia, São Paulo, Brazil \\ ${ }^{7}$ Grupo de Estudos de Doenças Inflamatórias Intestinais, Rio de Janeiro, Brazil \\ ${ }^{8}$ UNESA, Rio de Janeiro, Brazil \\ ${ }^{9}$ Gastroenterology Post-Graduation Program-PUC-Rio, Rio de Janeiro, Brazil \\ ${ }^{10}$ Neurology Post-Graduation Program, Universidade Federal do Estado do Rio de Janeiro (UERJ), Rio de Janeiro, \\ Brazil \\ ${ }^{11}$ Pharmacology Department-UFRJ, Rio de Janeiro, Brazil \\ ${ }^{12}$ Medical Genetics Service, IPPMG-Universidade Federal Rio de Janeiro, Rio de Janeiro, Brazil \\ ${ }^{13}$ Immunology Department, Teresópolis Medical School (UNIFESO), Teresópolis, Brazil \\ ${ }^{14}$ Clinical Immunology, Instituto de Pós-Graduação Médica Carlos Chagas (IPGMCC,) Rio de Janeiro, Brazil \\ Email: "maurogeller@gmail.com
}

Received 3 May 2016; accepted 12 July 2016; published 15 July 2016

Copyright (C) 2016 by authors and Scientific Research Publishing Inc.

This work is licensed under the Creative Commons Attribution International License (CC BY). http://creativecommons.org/licenses/by/4.0/

c) (7) Open Access

\section{Abstract}

Objectives: The purpose of this study was to evaluate and compare the use of propinox hydrochloride and scopolamine hydrochloride in patients presenting abdominal colic (abdominal pain), in

Corresponding author.

How to cite this paper: Rzetelna, H., et al. (2016) Clinical Assessment of the Use of Propinox Hydrochloride and Scopolamine Hydrochloride in the Treatment of Abdominal Colic: A Retrospective, Comparative Study. International Journal of Clinical Medicine, 7, 474-480. http://dx.doi.org/10.4236/ijcm.2016.77052 
terms of treatment efficacy and tolerability. Material \& Methods: This was an analytical, retrospective, comparative study based on hospital records of outpatients treated at Serviço de Clínica Médica do Hospital das Clínicas Costantino Otaviano (HCTCO) and at Santa Casa de Misericórdia do Rio de Janeiro, from 1988-1998. Subjects were divided into two groups: patients from Group 1 were treated with propinox hydrochloride, while patients from Group 2 were treated with scopolamine hydrochloride. Statistical analysis was performed using GraphPad Prism version 5.0. For comparison of categorical variables, we used the chi-squared or Fisher's test, while continuous variables were analyzed using ANOVA or the Student's T test. Results: A total of 1042 subjects were included, of which 525 were allocated to Group 1 and 517 to Group 2. Mean treatment duration was 9.166 days $( \pm 4.208)$ in Group 1 and 8.795 days $( \pm 5.052)$ in Group 2 , with no statistically significant difference in treatment duration between the two groups $(p=0.198)$. All subjects in Group 1 were treated with propinox $10 \mathrm{mg}$ ( 2 coated tablets, three times per day) while all subjects in Group 2 were treated with scopolamine hydrochloride $10 \mathrm{mg}(2$ coated tablets, three times per day). There were no statistically significant between-group differences in weight, BMI, heart rate, and respiratory rate at pre- and post-treatment; with the exception of higher post-treatment systolic blood pressure in Group 1, blood pressure measures also remained homogenous. Adverse events were reported among both treatment groups with no significant between-group difference in incidence $(p=0566)$. At pretreatment, pain intensity was more severe in Group $1(p=0.0257)$, while at post-treatment, there was no statistically significant difference between the two treatment groups $(p=0.895)$. There was a statistically significant improvement in pain intensity within both treatment groups $\left(\chi^{2}=631.4 ; \mathrm{df}=3 ; \mathrm{p}<0.0001\right.$ for Group 1 and $\chi^{2}=554.3 ; \mathrm{df}=3 ; \mathrm{p}<0.0001$ for Group 2). Conclusion: The results obtained in this study indicate a therapeutic equivalence between propinox hydrochloride and scopolamine hydrochloride. Both treatments demonstrated good efficacy and tolerability in the treatment of abdominal colic pain, in the population evaluated.

\section{Keywords}

\section{Abdominal Colic, Propinox Hydrochloride, Scopolamine Hydrochloride}

\section{Introduction}

The term abdominal colic is used to describe spasmodic abdominal pain, arising as a result of distension, inflammation, or obstruction. It is often characterized as a sharp, localized abdominal pain that increases, peaks, and subsides. While it is often a benign complaint, it may also be a sign of a more significant pathology, therefore a careful medical history and physical examination are crucial to the approach for a differential diagnosis. Treatment of abdominal colic includes pain relievers such as nonsteroidal anti-inflammatory drugs, as well as antispasmodic agents.

Propinox hydrochloride, also known as pargeverine hydrochloride, is an antispasmodic that presents a dual mechanism of pharmacologic action: musculotropic and anticholinergic. It functions as a musculotropic agent, acting directly on the visceral smooth muscle cells and conferring its antispasmodic activity [1]-[9]. The anticholinergic activity of propinox is derived from a moderate and non-selective blockade of muscarinic cholinergic fibers [1].

The pharmacological activity of propinox is exerted on the visceral smooth muscle cells of the digestive and genitourinary tract [1]-[9]. Its antispasmodic activity at the intestinal level presents an efficacy two to three times greater than papaverine. Its effects on digestive secretions are smaller than those produced by quaternary ammonium compounds, thus the antisylagogue action is relatively weak. In the cardiovascular system, propinox does not alter tensional values or heart rate. Additionally, there are no reported effects in the literature of effects on the respiratory tract, at therapeutic doses [2]-[5]. Propinox is indicated in the treatment of spasmodic states of the digestive, hepatobiliary, urinary or female genital tracts [1] [3].

Scopolamine hydrochloride is an anticholinergic drug that presents a high affinity for muscarinic receptors located on the smooth muscle cells of the gastrointestinal tract. Its anticholinergic activity exerts a muscle relaxant 
and spasmolytic effect. Scopolamine is derived from hyoscine, an alkaloid present in the leaves of the Duboisia plant, native to Australia, with a pharmacological potency twice that of atropine [1].

The basis of the therapeutic action of scopolamine is blockade of the action of acetylcholine in parasympathetic sites in smooth muscle and secretory glands. With this blockade, there is a decrease in motility of the urogenital and gastrointestinal tract, which renders scopolamine particularly useful in the treatment of spasms in these regions, commonly observed in gastroenteritis, colitis, irritable bowel syndrome, diverticulitis, biliary and urethtral colic, as well as in primary dysmenorrhea. It is also used in the prevention of gastrointestinal tract spasms prior to invasive radiological and diagnostic procedures. Scopolamine also acts on the glands of the oral cavity, gastrointestinal and respiratory tract, causing a reduction of activities and consequently of secretions [1] [3]. Scopolamine hydrochloride is indicated in the treatment of spasms of the gastrointestinal tract, biliary tract spasms and dyskinesias, and spasms of the genitourinary tract [1] [3] [15].

\section{Objectives}

The primary objective of this study was to evaluate the use of propinox hydrochloride in patients presenting abdominal colic (abdominal pain), in terms of treatment efficacy and tolerability. The secondary study objectives were to evaluate the use of scopolamine hydrochloride in patients presenting abdominal colic (abdominal pain), in terms of treatment efficacy and tolerability, and to compare the results of the use of propinox hydrochloride with those of scopolamine hydrochloride, in terms of treatment efficacy and tolerability.

\section{Material \& Methods}

This was an analytical, retrospective, comparative study. The study population consisted of outpatients treated at Serviço de Clínica Médica do Hospital das Clínicas Costantino Otaviano (HCTCO) and at Santa Casa de Misericórdia do Rio de Janeiro, from the period of 1988-1998, from which study data were drawn. After ethical committee approval (approval no. 523-10), data present in the hospital records of each patient were analyzed in order to fill in the clinical research form, including the results of physical exam (height, weight, heart rate, blood pressure), medical history, demographic data, the results of any laboratory exams, and the identification, pharmaceutical form, dosing and treatment duration with the study drug, in addition to the presence and severity of abdominal pain. Inclusion criteria called for subjects of both genders, above 18 years of age, who were attended at either hospital and prescribed treatment with either of the study drugs. Only data from subjects with at least two hospital visits were included. The subjects were divided into two groups, according to the drug received. Patients from Group 1 were treated with propinox hydrochloride, while patients from Group 2 were treated with scopolamine hydrochloride.

Statistical analysis was performed using GraphPad Prism version 5.0. For comparison of categorical variables, we used the chi-squared or Fisher's test, while continuous variables were analyzed using ANOVA or the Student's $\mathrm{T}$ test. The primary efficacy endpoint was the percentage of subjects presenting resolution (absence) of pain at the second hospital visit. Secondary endpoints included the percentage of subjects presenting mild, moderate, or severe pain at the second hospital visit in relation to the first visit, record of any adverse effects during the treatment period, and the results of any laboratory tests out of hospital reference range.

\section{Results}

A total of 1042 subjects were included, of which 525 were allocated to Group 1 and 517 to Group 2. Gender distribution was homogenous between treatment groups ( $\mathrm{p}=0.386)$; Group 1 included a total of $268(51.05 \%)$ male subjects and 257 (48.95\%) female subjects, while gender distribution in Group 2 was 278 (53.77\%) male subjects and 239 (46.23\%) female subjects. Ethnicity distribution was also homogenous between treatment groups $(\mathrm{p}=0.732)$. Mean subject age in Group 1 was $51.65( \pm 7.56)$ while in Group 2 it was $54.4( \pm 7.56)(\mathrm{p}<$ 0.001 for between-group difference).

Mean treatment duration was 9.166 days $( \pm 4.208)$ in Group 1 and 8.795 days $( \pm 5.052)$ in Group 2, with no statistically significant difference in treatment duration between the two groups $(\mathrm{p}=0.198)$. All subjects in Group 1 were treated with propinox $10 \mathrm{mg}$ (2 coated tablets, three times per day) while all subjects in Group 2 were treated with scopolamine hydrochloride $10 \mathrm{mg}$ ( 2 coated tablets, three times per day).

The results of the physical exam performed pre- and post-treatment and the respective between-visit differences are summarized in Table 1. At pretreatment, there was no statistically significant between-group difference 
Table 1. Pre and Post-treatment physical exam.

\begin{tabular}{ccccccc}
\hline Variable & $\begin{array}{c}\text { Group 1 } \\
\text { Pretreatment }\end{array}$ & Post-treatment & $\begin{array}{c}\text { Between-visit } \\
\text { difference }\end{array}$ & $\begin{array}{c}\text { Group 2 } \\
\text { Pretreatment }\end{array}$ & Post-treatment & $\begin{array}{c}\text { Between-visit } \\
\text { difference }\end{array}$ \\
\hline Weight (kg) & $67.18( \pm 11.44)$ & $67.15( \pm 11.39)$ & $\mathrm{p}=0.284$ & $68.19( \pm 11.25)$ & $68.09( \pm 11.18)$ & $\mathrm{p}=0.0134$ \\
$\mathbf{B M I ~ ( k g / \mathbf { c m } ^ { 2 } )}$ & $24.18( \pm 2.802)$ & $24.5( \pm 4.945)$ & $\mathrm{p}=0.0582$ & $24.11( \pm 2.54)$ & $24.1( \pm 2.508)$ & $\mathrm{p}=0.435$ \\
$\begin{array}{c}\text { Systolic blood } \\
\text { pressure (mmHg) } \\
\text { Diastolic blood } \\
\text { pressure (mmHg) }\end{array}$ & $122.2( \pm 8.25)$ & $122.4( \pm 8.67)$ & $\mathrm{p}=0.387$ & $121.3( \pm 7.29)$ & $121.3( \pm 7.304)$ & $\mathrm{p}=0.875$ \\
$\begin{array}{c}\text { Heart rate (bpm) } \\
\text { Respiratory rate } \\
\text { (ipm) }\end{array}$ & $68.6( \pm 9.66)$ & $78.23( \pm 9.89)$ & $\mathrm{p}<0.0001$ & $78.16( \pm 8.17)$ & $78.1( \pm 7.662)$ & $\mathrm{p}=0.781$ \\
\hline
\end{tabular}

Data are means $( \pm \mathrm{SD})$ and $\mathrm{p}$ values.

in weight ( $p=0.15)$; this finding was maintained post-treatment $(\mathrm{p}=0.181)$. BMI did not vary significantly between treatment groups at either study visit ( $p=0.675$ for pretreatment and $p=0.099$ for post-treatment). Pretreatment blood pressure measures did not vary between treatment groups $(p=0.669$ for systolic blood pressure and $\mathrm{p}=0.1833$ for diastolic blood pressure); at post-treatment, systolic blood pressure was higher $(\mathrm{p}=0.0258)$ among subjects in Group 1 while diastolic blood pressure was homogenous between treatment groups $(\mathrm{p}=$ 0.8105). Mean heart rate was homogenous between treatment groups at both pretreatment $(p=0.2114)$ and post-treatment $(p=0.234)$. Respiratory rate was also homogenous between both groups $(p=0.725$ for pretreatment and $\mathrm{p}=0.632$ at post-treatment).

There was no statistically significant between-group difference in the number of subjects using concomitant medications $(p=1.0)$. At pretreatment, 87 in each treatment group reported use of concomitant medications. At post-treatment, this number reduced to 27 subjects in each treatment group.

Adverse events were reported among both treatment groups, with 133 subjects in Group 1 reporting adverse events during the treatment period and 123 subjects in Group 2. The incidence of adverse events occurring during the treatment period did not vary between treatment groups $(p=0.566)$. Table 2 summarizes the adverse events by system and patient group.

Figure 1 summarizes the results of the assessments of pain severity pre and post-treatment. At pretreatment, pain intensity was more severe in Group 1 ( $p=0.0257)$, while at post-treatment, there was no statistically significant difference between the two treatment groups $(\mathrm{p}=0.895)$. There was a statistically significant improvement in pain intensity within both treatment groups $\left(\chi^{2}=631.4\right.$; $\mathrm{df}=3$; $\mathrm{p}<0.0001$ for Group 1 and $\chi^{2}=554.3$; $\mathrm{df}=3$; $\mathrm{p}<0.0001$ for Group 2).

\section{Discussion}

Although this was a retrospective study with inherent limitations in data availability, the study drugs were well tolerated in both treatment groups. This finding is consistent with data reported in the literature on clinical administration of both agents.

Clinical safety and efficacy studies have demonstrated a good tolerability of propinox. De los Santos et al. (1999) evaluated the efficacy and tolerability of propinox administered intravenously at doses of 10, 20, and 30 mg versus placebo in 350 patients presenting severe acute biliary pain. Propinox significantly and progressively reduced pain at all doses employed, 20, 60, and 120 minutes after administration, with the highest results obtained after 120 minutes at the doses of $20 \mathrm{mg}$ and $30 \mathrm{mg}$. The drug was well tolerated at all doses, with no dropouts due to adverse effects. Mouth dryness was the only adverse event that occurred more frequently among the treated subjects as compared to the placebo group, and was observed only among patients receiving the doses of 20 and $30 \mathrm{mg}$. No significant changes in heart rate or blood pressure were observed among treated subjects [10].

Another clinical study evaluating the safety and efficacy of propinox by intravenous route used the same doses of 10, 20, and $30 \mathrm{mg}$ versus placebo in 400 patients presenting moderate to severe colic-type abdominal pain secondary to a functional pathology (irritable bowel syndrome and dyspepsia). Propinox was more effective in reducing pain compared to placebo at the three doses administered. In the assessment performed 120 minutes following drug administration, there was a significant difference in the percentage of subjects with pain reduction in 


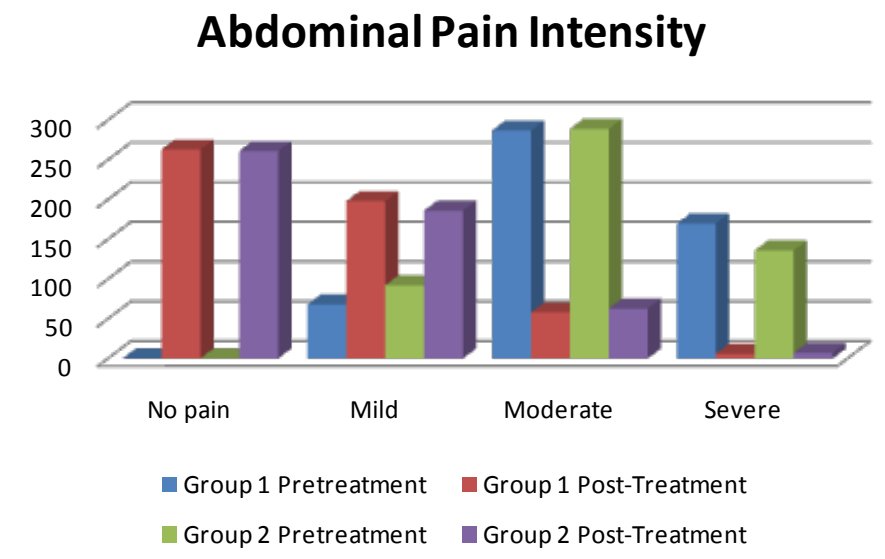

Figure 1. Abdominal pain intensity at pretreatment and post-treatment.

Table 2. Pre- and post-treatment physical exam.

\begin{tabular}{ccc}
\hline System affected & Number of Subjects per Treatment Group \\
\hline Cardiovascular system & Group 1 & Group 2 \\
\hline Cardiovascular system/Nervous system & 7 & 7 \\
Endocrine system & 1 & 0 \\
Endocrine system/Cardiovascular system & 43 & 42 \\
Endocrine system/Nervous system & 1 & 4 \\
Endocrine system/Respiratory system & 1 & 0 \\
Endocrine system/Gastrointestinal tract & 1 & 3 \\
Nervous system & 5 & 13 \\
Nervous system/Gastrointestinal tract & 20 & 1 \\
Respiratory system & 1 & 1 \\
Gastrointestinal tract & 0 & 25 \\
Gastrointestinal tract/Endocrine system & 28 & 2 \\
Gastrointestinal tract/Nervous system & 2 & 0 \\
Urinary tract & 1 & 23
\end{tabular}

Data are $n$.

favor of the 20 and $30 \mathrm{mg}$ doses. The authors related dry mouth as the most frequent adverse event reported at doses of $20 \mathrm{mg}$ and $30 \mathrm{mg}$. No change in blood pressure or heart rate was observed among these subjects [11].

The efficacy and safety of propinox was assessed by Mezzotero et al. (1995) in the treatment of patients with mild to moderate abdominal colic pain resulting from biliary, intestinal, renal-pelvic, urethral, or female genital pathology (dysmenorrhea). One hundred and six subjects were treated with a dose of $10 \mathrm{mg}$ administered orally. Pain intensity decreased by $43 \%$ thirty minutes after administration of a single dose. The most frequently reported adverse effects were flushing and pruritis. One subject developed a clinical picture of cutaneous allergy with bipalpebral edema requiring parenteral administration of antihistamines [12].

The efficacy and tolerability of parenterally administered propinox was assessed by Olmos et al., (2003), at the doses of 20 or $30 \mathrm{mg}$, among patients presenting with colonic spasm induced by colon exam among subjects with irritable bowel. Both doses of propinox were effective in reversing the colonic spasm, increasing colonic diameter, and reducing abdominal pain. The adverse events reported during the treatment were mild and transitory, with a single case of blurred vision, one case of dry mouth and one of pruritis among the 30 subjects who 
underwent treatment [13].

An oral dose of $10 \mathrm{mg}$ was used by Pulpeiro et al. (2000) to compare the analgesic efficacy and assess changes in defecation rhythm, abdominal distension, frequency of pain crises, and sensation of incomplete evacuation as compared to treatment with a placebo. The double-blind, randomized treatment period lasted 4 weeks and included 75 subjects with irritable bowel syndrome, with 4 daily doses of the study drug. The group treated with propinox presented a significant and progressive reduction over the 28 day treatment period in intensity of abdominal pain, weekly frequency of pain episodes, and abdominal distension, greater than that observed in the group treated with placebo. The most frequent adverse effects were headaches, nausea, and dry mouth, however no dropouts due to adverse effects were recorded [14].

Several clinical studies have been performed assessing the safety and efficacy of scopolamine. Ten placebocontrolled clinical trials assessed this drug in the treatment of abdominal pain and discomfort, with a total of 3699 subjects, of which 911 received the drug in oral form $(n=868)$ or rectal form $(n=43)$ and 2788 subjects received paracetamol, placebo, or a combination of scopolamine with other drugs. Treatment duration varied in the studies from a single $20 \mathrm{mg}$ dose with a 4 hour observation period to a three-month treatment period with a dose of $10 \mathrm{mg}$ four times per day. The maximum daily dose varied between 20 - $200 \mathrm{mg}$ over 10 days. Scopolamine was considered beneficial in all of these studies, with statistically superior efficacy over placebo in at least one variable in each study [17]-[26]. Of these ten studies, seven included a small number of subjects $(<50)$ treated with the drug, and were performed prior to the establishment of the Good Clinical Practice and International Conference on Harmonisation Guidelines. Therefore, although the results of these seven studies were favorable, they are of limited value in assessing the efficacy of the drug.

Three more recent comparative studies, including 712 [17], 818 [21], and 1637 [23] subjects, respectively, used doses between 30 and $60 \mathrm{mg}$ and treatment duration varied between 4 days and 3 weeks, respectively. The results of the first study demonstrated that scopolamine administered orally or rectally resulted in a significant improvement of pain in comparison to treatment with placebo [21]. In a double-blind, comparative, randomized study, parallel groups of patients with irritable bowel syndrome were treated with scopolamine + paracetamol, scopolamine alone, paracetamol alone, or placebo over the course of four weeks. At the end of the treatment period, $75 \%$ of the patients in the groups treated with scopolamine had significant improvement in symptoms, with a statistically significant improvement in abdominal pain intensity in the groups treated with scopolamine compared to subjects treated only with paracetamol or placebo [17]. In a clinical trial assessing 1637 subjects, the efficacy and tolerability of three daily doses of scopolamine $10 \mathrm{mg}$, paracetamol $500 \mathrm{mg}$, a combination of the two drugs, or placebo, was assessed over a three week treatment period. The intensity and frequency of the pain decreased significantly in the scopolamine treatment groups as compared to placebo, and no difference was observed between the active treatments [23].

\section{Conclusion}

The results obtained in this study indicate a therapeutic equivalence between propinox hydrochloride and scopolamine hydrochloride. Both treatments demonstrated good efficacy and tolerability in the treatment of abdominal colic pain, in the population evaluated.

\section{Acknowledgements}

The authors would like to thank Renato Kaufman, Breno Lorch, Silvia Maciel, and Diane Bergamim, Natasha Cytrynbaum, and Klaudia Ciszewianka for help with data retrieval, tabulation, and verification.

\section{References}

[1] Sweetman, S (Ed.) (2007) Martindale: The Complete Drug Reference. 35th Edition, Pharmaceutical Press, London.

[2] Baistrocchi, R.L., Orti, E., de los Santos, A.R., et al. (1999) Antispasmodic Action of Propinox on the Isolated Human Gallbladder: Possible Mechanism of Action. Acta Physiologica, Pharmacologica et Therapeutica Latinoamericana, 49, 161-169.

[3] Hardman, J.G., Limbird, L.E. and Gilman, A.G. (2001) Goodman \& Gilman's The Pharmacological Basis of Therapeutics. 10th Edition, McGraw-Hill, New York.

[4] Sasaki, D., Kido, A. and Yoshida, Y. (1984) Effect of Antispasmodic Drugs on Coloinc Motility. Part I: Laboratory Study of the Dog. International Journal of Clinical Pharmacology, Therapy, and Toxicology, 22, 333-337. 
[5] Baistrocchi, R.L., Orti, E., de los Santos, A.R., et al. (1999) Comparison of the Isolated Human and Guinea-Pig Gallbaldder Strip Models in the Assessment of Antispasmodic Drugs. Methods and Findings in Experimental and Clinical Pharmacology, 21, 659. http://dx.doi.org/10.1358/mf.1999.21.10.795736

[6] Sasaki, D., Kido, A. and Yoshida, Y. (1984) Effect of Antispasmodic Drugs on Coloinc Motility. Part II: Clinical Study in Man. International Journal of Clinical Pharmacology, Therapy, and Toxicology, 22, 338-341.

[7] Forbes, O.C. and Marshall, P.B. (1951) Pharmacology of Benzilic Acid Derivaties. British Journal of Pharmacology, 6, 634-642.

[8] Weaver, L.C., Abreu, B.E., Alexander, W.M., et al. (1959) Pharmacologic Properties of Certain Beta-diethylaminothyl4-alkoxybenzilates. Archives Internationales de Pharmacodynamie, 121, 415.

[9] Baistrocchi, R., Orti, E., de los Santos, A.R., et al. (1997) Antispasmodic Action of Propinoxhydrochloride (P) on the Gallbladder. Possible Mechanism of Action. Medicina, 57, 61.

[10] de los Santos, A.R., Martí, M.L., di Girolamo, G., et al. (1999) Propinox in Biliary Colic: A Multicenter, Randomized, Prospective and Parallel Double-Blind Study of Three Doses of Propinox versus Placebo in Acute Biliary Colic Pain. International Journal of Tissue Reactions, 21, 13-18.

[11] Di Giroamo, G., de los Santos, A.R., Marti, M.L., et al. (2000) Propinox in Intestinal Colic: Multicenter Randomized Prospective Double-Blind Study of Three Doses of Propinox vs. Placebo in Acute Intestinal Colic Pain. International Journal of Clinical Pharmacology Research, 20, 31-40.

[12] Mezzotero, O., Arriaga, A.A.S. and Tobar, J.C. (1995) [Clinical Trial with Propinox (10 mg) Pearls in Abdominal Colic: A Multicenter Study]. Prensa Medica Argentina, 82, 428.

[13] Olmos, J.Á., Seehaus, A., Peralta, D., et al. (2003) [Efficacy of Propinox in Reverting Colonic Spasm during Colon Enema in Patients with Irritable Bowel]. Medicina Interna, 3, 127.

[14] Pulpiero, A., Marí, M.L., de los Santos, A.R., et al. (2000) [Propinox in Irritable Bowel Syndrome]. Prensa Medica Argentina, 87, 299.

[15] Evangelista, S. (2004) Quaternary Ammonium Derivatives as Spasmolytics for Irritable Bowel Syndrome. Current Pharmaceutical Design, 10, 3561. http://dx.doi.org/10.2174/1381612043382972

[16] Tytgat, G.N. (2007) Hysocine Butylbromide: A Review of Its Use in the Treatment of Abdominal Cramping and Pain. Drugs, 67, 1343-1357. http://dx.doi.org/10.2165/00003495-200767090-00007

[17] Schafer, E. and Ewe, K. (1990) The Treatment of Irritable Colon: Efficacy and Tolerance of Buscopan Plus, Buscopan, Paracetamol and Placebo in Ambulatory Patients with Irritable Colon. Fortschritte der Medizin, 108, 488-492.

[18] Sanchez Martinez, J. and Goiz Durán, I. (1988) Clinical Assessment of the Tolerability and Effect of IK-19 in Tablet Form on Pain of Spastic Origin. Investigacion Medica Internacional, 15, 63.

[19] Nigam, P., Kapoor, K.K., Rastog, C.K., et al. (1984) Different Therapeutic Regimens in Irritable Bowel Syndrome. The Journal of the Association of Physicians of India, 32, 1041-1044.

[20] Miyoshi, A. (1976) A Multi-Centre, Double-Blind Evaluation against Placebo of the Therapeutic Effect of HyoscineN-butylbromide in Patients with Abdominal Pain. Pharmatherapeutica, 1, 46.

[21] De Gregorio, M., Damiani, S. and Gatta, G. (1969) Antalgic Properties of Proxazole: Double Blind Study in Visceral Algoplastic Conditions. Panminerva Medica, 11, 436.

[22] Ritchie, J.A. and Truelove, S.C. (1979) Treatment of Irritable Bowel Syndrome with Lorazepam, Hyoscine Butylbromide, and Ispaghula Husk. BMJ, 1, 376. http://dx.doi.org/10.1136/bmj.1.6160.376

[23] Mueller-Lissner, S., Tytgat, G.N., Paulo, L.G., et al. (2006) Placebo- and Paracetamol-Controlled Study on the Efficacy and Tolerability of Hysoscine Butylbromide in the Treatment of Patients with Recurrent Crampy Abdominal Pain. Alimentary Pharmacology \& Therapeutics, 23, 1741. http://dx.doi.org/10.1111/j.1365-2036.2006.02818.x

[24] Navarro Martinez, P. (1972) Statistical Double-Blind Study on the Therapeutic Preference of Chronic Gastropathic Subjects in Acute Crises. Revue Médicale Suisse, 4, 77.

[25] Metzger, K.H. (1979) The Effect of Anticholinergic Agents on Caudal Intestinal Sections: Experimental Investigations into Motility. Ärztliche Praxis, 21, 923.

[26] Sieg, H. (1974) Double Blind Test Using Hyoscine-N-butyl Bromide (Buscopan) to Reduce Pain in Ulcus Ventriculi. Zeitschrift für Gastroenterologie, 12, 235. 


\section{Submit or recommend next manuscript to SCIRP and we will provide best service for you:}

Accepting pre-submission inquiries through Email, Facebook, LinkedIn, Twitter, etc.

A wide selection of journals (inclusive of 9 subjects, more than 200 journals)

Providing 24-hour high-quality service

User-friendly online submission system

Fair and swift peer-review system

Efficient typesetting and proofreading procedure

Display of the result of downloads and visits, as well as the number of cited articles

Maximum dissemination of your research work

Submit your manuscript at: http://papersubmission.scirp.org/ 